\title{
O SEXO: A CUMPLICIDADE PROFISSIONAIS DO SEXO: A CUMPLICIDADE
MO ENFRENTAMENTO DAS VULNERABILIDADES
}

\author{
Joice Moreira Schmalfuss* \\ Everton Boff** \\ Ana Lucia Lago*** \\ Daiane Gnoatto***** \\ Junir Antônio Lutinski****** \\ Lucimare Ferraz ${ }^{* * * * * * * *}$ \\ Maria Assunta Busato*********
}

\begin{abstract}
Resumo
Este artigo objetiva analisar as vulnerabilidades do trabalho de profissionais do sexo atuantes na rua e suas formas de enfrentamento. Trata-se de um estudo qualitativo, transversal e reflexivo. Dez mulheres participaram de dois encontros que aconteceram na modalidade roda de conversa, em abril de 2017, em motéis do tipo drive in, no município de Chapecó, Santa Catarina, Brasil. As informações foram coletadas por meio de questionário, registradas em diário de campo e submetidas à análise de conteúdo do tipo temática. A interpretação dos dados se deu mediante subjetividade e análise reflexiva crítica dos autores, desvelando-se dois temas: "As vulnerabilidades do ofício" e o "Enfrentamento das vulnerabilidades". As profissionais do sexo relataram vulnerabilidades de ordem individual, social e programática, incluindo aspectos ligados a questões de gênero e de poder, de situações que envolvem violência física, sexual e moral, além de exposição a agravos relacionados à saúde física e emocional. Observou-se uma complexidade de variáveis influenciando nas situações de vulnerabilidade, mas também muitas formas de enfrentamento perante as diferentes
\end{abstract}

\footnotetext{
* Enfermeira, doutoranda do Programa de Pós-Graduação em Ciências da Saúde da Universidade Comunitária da Região de Chapecó (UNOCHAPECÓ), docente da Universidade Federal da Fronteira Sul (UFFS) - Campus Chapecó. E-mail: joicemschmalfuss@gmail.com

** Farmacêutico, doutorando do Programa de Pós-Graduação em Ciências da Saúde da Universidade Comunitária da Região de Chapecó (UNOCHAPECÓ), docente da Universidade do Oeste de Santa Catarina (UNOESC) - Campus São Miguel do Oeste. E-mail: everton.boff@unochapeco.edu.br

*** Médica, mestranda do Programa de Pós-Graduação em Ciências da Saúde da Universidade Comunitária da Região de Chapecó (UNOCHAPECÓ), docente da UNOCHAPECÓ e da Universidade Federal da Fronteira Sul (UFFS) - Campus Chapecó. E-mail: analago@unochapeco.edu.br

**** Psicóloga, discente especial do Programa de Pós-Graduação em Ciências da Saúde da Universidade Comunitária da Região de Chapecó (UNOCHAPECÓ). E-mail: daia_tto@unochapeco.edu.br

***** Biólogo, doutor em Biodiversidade Animal, docente do Programa de Pós-Graduação em Ciências da Saúde da Universidade Comunitária da Região de Chapecó (UNOCHAPECÓ). E-mail: junir@unochapeco.edu.br

****** Enfermeira, doutora em Saúde Coletiva, docente do Programa de Pós-Graduação em Ciências da Saúde da Universidade Comunitária da Região de Chapecó (UNOCHAPECÓ).E-mail:1ferraz@unochapeco.edu.br

******* Bióloga, doutora em Biologia, docente do Programa de Pós-Graduação em Ciências da Saúde da Universidade Comunitária da Região de Chapecó (UNOCHAPECÓ).E-mail: assunta@unochapeco.edu.br
} 
situações vivenciadas. A partir das experiências e vivências de cada mulher, destacam-se as estratégias de cumplicidade e apoio utilizadas entre as profissionais como importante forma de enfrentamento e de proteção.

Palavras-chave: Trabalho sexual. Grupos de risco. Vulnerabilidade em saúde. Infecções Sexualmente Transmissíveis. Violência.

\section{Introdução}

$\mathrm{Na}$ sociedade atual ainda persistem ofícios que são considerados menos dignos que outros, dentre eles está a prostituição, a qual consiste em oferecer serviços sexuais em troca de pagamento. Profissionais do sexo proporcionam sexo, fantasias e prazer, por meio de prestação de serviços, muitas vezes vistos como clandestinos (SILVA; CAPPELLE, 2015). Diante de todo o estigma e estereótipo social que a atividade comporta, trata-se de "uma das ocupações mais antigas do mundo" (DOURADO et al., 2013, p. 4139).

De acordo com a Classificação Brasileira de Ocupação (CBO), do Ministério do Trabalho (BRASIL, 2017), o número 5198-05 corresponde à ocupação "profissional do sexo" (também titulada como garota de programa, meretriz, messalina, michê, mulher da vida, prostituta, trabalhadora do sexo). Como descrição sumária da atividade, estas profissionais "buscam programas sexuais, atendem e acompanham clientes e participam em ações educativas no campo da sexualidade. As atividades são exercidas seguindo normas e procedimentos que minimizam as vulnerabilidades da profissão" (BRASIL, 2017).

Conforme o mencionado, embora o Ministério do Trabalho afirme que as atividades de profissionais do sexo sejam exercidas de forma a minimizar as vulnerabilidades, reflete-se que as condições gerais de exercício fazem com que as pessoas atuantes nessa atividade sejam classificadas como vulneráveis. Aliado a isso, a prostituição trata de prática que envolve o corpo como principal ferramenta de trabalho, enquadrando-se em diferentes contextos e cenários de atuação e envolvendo diferentes sujeitos que pagam pela prestação de serviços sexuais.

O conceito do termo "vulnerabilidade" vem do campo dos Direitos Universais do Homem, no qual denomina sujeitos e grupos desamparados em seus direitos (AYRES et al., 2009). A partir dos anos 1990, este conceito passou a ser usado na área da saúde, especialmente em intervenções realizadas para combater a epidemia da Síndrome da Imunodeficiência Adquirida (AIDS) (AYRES et al., 2009).

O enfrentamento das vulnerabilidades visa a extrapolar a redução dos riscos (AYRES et al., 2009). O enfoque daqueles que são vulneráveis objetiva descobrir como os movimentos sociais e culturais, juntamente com 
fatores individuais, podem influenciar na ocorrência de situações de risco (MALAGÓN-OVIEDO; CZERESNIA, 2015).

Segundo Sánchez e Bertolozzi (2007), as vulnerabilidades biológica, existencial e social se caracterizam como uma junção de fatos que podem potencializar as ameaças e se materializar em agravos à saúde da população. Dessa forma, a determinação biológica pode estar envolvida com alguma forma de limitação e a existencial e social podem impossibilitar o uso dos direitos e autonomia de um indivíduo. Esses níveis são inseparáveis e configuram a vulnerabilidade como multifatorial, já que suas decorrências podem afetar o sujeito como um todo.

Para elucidar a forma como as vulnerabilidades são abordadas neste artigo, adotou-se a classificação de Ayres et al. (2009, p. 127), a qual considera três eixos interligados entre si, sendo eles:

Componente individual: diz respeito ao grau e à qualidade da informação de que os indivíduos dispõem sobre o problema; à capacidade de elaborar essas informações e incorporá-las aos seus repertórios cotidianos de preocupações; e, finalmente, ao interesse e às possibilidades efetivas de transformar essas preocupações em práticas protegidas e protetoras.

Componente social: diz respeito à obtenção de informações, às possibilidades de metabolizá-las e ao poder de incorporar às mudanças práticas, o que não depende só dos indivíduos, mas de aspectos, como acesso a meios de comunicação, escolarização, disponibilidade de recursos matérias, poder de influenciar decisões políticas, possibilidade de enfrentar barreiras culturais, estar livre de coerções violentas, ou poder defender-se delas etc.

Componente programático: quanto maior for o grau e a qualidade de compromisso, recursos, gerenciais, monitoramento de programas nacionais, regionais ou locais de prevenção e de cuidado paliativo.

Analogamente, Malagón-oviedo e Czeresnia (2015, p. 243) afirmam que "[...] em cada situação de vulnerabilidade, o organismo, em referência a seu meio, experimenta as consequências da transgressão do preceito relacional". Nesse contexto, a vulnerabilidade requer uma atitude flexível do sujeito, de forma que este adote recursos que ultrapassem as circunstâncias negativas perante determinada situação, mesmo com as influências do meio neste processo (MALAGÓN-OVIEDO; CZERESNIA, 2015).

Vivências dos indivíduos no nível social mostram que situações que remetem à fragilidade e à resiliência fazem parte da existência do ser humano, de forma que se entrelaçam nas experiências dos sujeitos. A resiliência possibilita uma fonte de alternativas, de prosseguir, a fragilidade refere-se à falta de vontade de seguir (MALAGÓN-OVIEDO; CZERESNIA, 2015). 
Brown e Sanders (2017) sugerem que a vulnerabilidade pode ser um conceito útil para discussões de temáticas que se originam de trabalhos que tornam os sujeitos vulneráveis, dentre eles, a oferta de serviços sexuais. Nesse contexto, neste estudo qualitativo, transversal e reflexivo, caracterizase como objetivo analisar as vulnerabilidades do trabalho de profissionais do sexo atuantes na rua e suas formas de enfrentamento. A primeira sessão se dedica à caraterização do estudo e o percurso metodológico. A segunda apresenta os resultados e discussão com ênfase para a análise temática das falas contidas nos diários de campo, a qual permitiu elencar os seguintes temas: "As vulnerabilidades do ofício" e "Enfrentamento das vulnerabilidades".

\section{A caracterização do estudo e o encontro com as profissionais do sexo}

Trata-se de um estudo qualitativo, transversal e reflexivo, desenvolvido a partir de atividades vinculadas à disciplina "Vulnerabilidades e Riscos em Saúde", componente curricular optativo para os cursos de Mestrado e Doutorado do Programa de Pós-Graduação Stricto Sensu em Ciências da Saúde (PPGCS), da Universidade Comunitária da Região de Chapecó (UNOCHAPECÓ), Santa Catarina, Brasil.A disciplina, com carga horária de 45 horas/aula, se insere na linha de pesquisa Saúde e Ambiente e possui como objetivo geral compreender as situações de risco e vulnerabilidade presentes no processo saúde-doença da realidade regional e nacional, propondo ações de enfrentamento aos agravos à saúde.

Partiu-se da necessidade de compreender as situações de vulnerabilidade presentes no trabalho de profissionais do sexo atuantes em ruas, na área urbana de Chapecó, bem como investigar as formas de enfrentamento das vulnerabilidades identificadas. A aproximação com as profissionais se deu por intermédio de colaboradores do Grupo de Apoio à Prevenção da AIDS (GAPA), seção de Chapecó, cuja organização foi fundada em 1989 com o objetivo de manter o direito, o respeito e a liberdade dos indivíduos contaminados com o vírus da imunodeficiência humana (HIV). Atualmente, o GAPA visa à prevenção da população para a não contaminação por diversos vírus, dando uma importância maior ao HIV e às hepatites, principalmente quando essa transmissão é de cunho sexual. Ainda, o GAPA proporciona à comunidade medidas preventivas para a não disseminação de Infecções Sexualmente Transmissíveis (IST), assim como a diminuição do preconceito e da exclusão social de pessoas com IST (GAPA, 2017).

Mediante contato prévio, dois encontros foram realizados com profissionais do sexo, em abril de 2017. Ambos ocorreram conforme 
solicitado pelas profissionais, em local e ambiente de trabalho delas, motéis do tipo drive in. Observou-se que esses locais favoreceram o diálogo, além de possibilitar segurança e privacidade às mulheres.

A coleta de dados se deu por meio de rodas de conversa que tiveram duração aproximada de duas horas, cada uma, e contaram com a participação de três mulheres profissionais em uma reunião e sete mulheres em outra. As conversas foram permeadas pelo compartilhamento de chimarrão e, no centro da roda, uma mesa organizada com salgados, doces e refrigerantes era acessada a todo o momento pelos presentes, o que favoreceu um clima de descontração e deu o tom de uma conversa informal entre os estudantes, os professores e os funcionários do GAPA que acompanharam o diálogo com as profissionais.

Previamente, foi elaborado um questionário focado na identificação das vulnerabilidades e nas formas de enfrentamento. Todas as informações provenientes das rodas de conversa foram registradas em diários de campo e, posteriormente, discutidas à luz de referencial teórico sobre o tema. $\mathrm{O}$ diário de campo é o instrumento mais simples de registro de dados, sendo fundamental para o pesquisador. Nele, todas as observações, reflexões e experiências são registradas para posterior seleção dos dados mais relevantes (VÍCTORA, 2000).

As informações foram analisadas conforme referencial de análise de conteúdo do tipo temática, proposta por Bardin (2011). Este modelo de análise compreende três etapas, sendo elas: pré-análise, exploração do material e, por fim, tratamento dos resultados obtidos, inferência e interpretação. A interpretação dos dados se deu mediante subjetividade e análise reflexiva crítica dos autores.

\section{Resultados e discussão}

O tempo de atuação como profissional do sexo das participantes deste estudo varia de poucos meses a 25 anos. Estudo realizado com 310 prostitutas atuantes em diferentes zonas da cidade de Teresina-Piauí verificou que mais da metade $(65,8 \%)$ das entrevistadas exerciam a função há mais de seis anos (MADEIRO; RUFINO, 2012).

Dificuldades financeiras das mulheres participantes foram responsáveis por relatos de abandono e retorno à prostituição por diversas vezes. Nesse contexto, Burbulhan, Guimarães e Bruns (2012) apontaram que o dinheiro constitui o motivo mais importante para as profissionais do sexo continuarem na prostituição.

A exemplo das participantes no presente estudo (atuantes na rua), pesquisa realizada com população nas mesmas condições, em dez cidades brasileiras, verificou que 38,7\% das entrevistadas referiram trabalhar em 
ponto de rua (LIMA et al., 2017). Para muitas pessoas, estar na rua, pode ser sinônimo de perigo; porém, para as profissionais do sexo entrevistadas percebeu-se que esta condição está atrelada à sensação de liberdade e, ao mesmo tempo, segurança. Estar aos arredores do motel onde a prestação de serviços acontece, além de facilitar o contato inicial com o cliente, permite que a mulher tenha a quem recorrer diante de qualquer ameaça. Da mesma forma, Fernandes, Borges e Lôbo (2017, p. 477) afirmaram que na prostituição de rua "[...] criam-se formas simbólicas de uso do espaço, onde se esquivar em sombras de árvores e postes possibilita o exercício da atividade e, ao mesmo tempo em que dá a sensação de segurança”.

Quanto ao valor cobrado pelos programas, em pesquisa realizada por Lima et al. (2017), 58,1\% das mulheres cobravam entre um e 49 reais; e $77,2 \%$ das profissionais afirmaram realizar entre um e cinco programas por dia, fatos semelhantes aos verificados em conversa com as profissionais do sexo deste estudo. Já em pesquisa realizada com prostitutas de TeresinaPiauí, 76,5\% das entrevistadas cobravam entre 10 e 50 reais para um programa (MADEIRO; RUFINO, 2012). É relevante mencionar que as profissionais que participaram das rodas de conversa relataram existir um acordo verbal entre elas para que um mesmo valor seja cobrado para cada programa a fim de evitar concorrência desleal e, consequentemente, gerar conflitos entre elas.

A análise temática das falas contidas nos diários de campo permitiu elencar os seguintes temas: "As vulnerabilidades do ofício"e "Enfrentamento das vulnerabilidades".

\section{As vulnerabilidades do ofício}

As profissionais do sexo apresentam vulnerabilidades, atreladas aos três eixos classificados por Ayres et al. (2009), sendo: componente individual, social e programático.

Falas que remetem a questões morais e sociais estiveram presentes nas rodas de conversa, principalmente exemplificadas por vulnerabilidades, tais como o preconceito das profissionais para com elas próprias e pelo trabalho exercido, seja por pessoas da coletividade e/ou por membros das suas famílias. A prostituição é uma prática sentenciada pela sociedade, tanto por aspectos relacionados à moral e à ética, quanto por estar ligada à ideia de propagação de doenças, por estimular a infidelidade e, consequente, abalo na configuração familiar (DOURADO et al., 2013).

Estudo conduzido por Lima et al. (2017) refere que, de 2.523 profissionais do sexo incluídas como participantes da pesquisa, $66,4 \%$ se sentiram discriminadas pela profissão. Também foram relatadas situações de assédio por estarem expostas na rua e de falta de educação praticadas pelos 
clientes e pela sociedade de uma forma geral. Outro estudo que objetivou investigar quais os aspectos que interferem na relação da profissional do sexo com seu cliente, apontou que a relação entre eles geralmente é difícil, visto que os clientes costumam querer impor suas condições (BURBULHAN; GUIMARÃES; BRUNS, 2012).

Uma vulnerabilidade social detectada nos relatos de todas as profissionais do sexo foi a ausência de contribuição para a previdência social. Este fato foi apresentado como gerador de ansiedades e inseguranças em relação ao futuro que se configura incerto quanto às questões financeiras e aposentadoria.

Vulnerabilidades aos mais variados tipos de violências foram constatadas e relacionadas ao contexto do trabalho, bem como à atuação na rua, fatos que expõem as profissionais do sexo a agressões verbais e físicas por clientes (durante os programas) e por colegas de trabalho (nas disputas por ponto e por clientes), assaltos, atropelamentos e xingamentos.

É frequente a caracterização de profissionais do sexo como vulneráveis, principalmente no intuito de pontuar os altos índices de violência enfrentados pelas trabalhadoras sexuais atuantes na rua (BROWN; SANDERS, 2017). Mesmo que pareça comum, é fato que as violências física e sexual são fatores de vulnerabilidade que acometem esta parcela da população (CONNERS et al., 2016).

Uma revisão sistemática de literatura sobre prostitutas de rua apontou que estas estão expostas a altos riscos de sofrerem violência (LOVE, 2015). Pesquisa com 140 profissionais do sexo de rua, em Taiwan, investigou os fatores associados ao risco de violência e assalto por outros profissionais do sexo e clientes, e corrobora os achados do presente estudo, ao passo que os resultados mostraram que os riscos de violência causada por clientes e por outras profissionais do sexo estão relacionados entre si (CHANG; WENG, 2015).

No que concerne às violências entre mulheres profissionais do sexo, 59,5\% das 2.523 participantes do estudo realizado por Lima et al., (2017) relataram já ter sofrido violência verbal; $38,1 \%$ afirmaram terem sido agredidas fisicamente por qualquer agressor e $11,7 \%$ por clientes; e $37,8 \%$ já foram violentadas sexualmente alguma vez na vida.

A exposição a bebidas e drogas também torna as profissionais vulneráveis, já que, além dos clientes utilizarem tais substâncias, pode haver consumo pelas próprias mulheres, seja conscientemente ou de maneira forçada. Lima et al., (2017) mostraram que 73,7\% das entrevistadas referiram fazer uso de álcool e 30,9\% utilizaram drogas como maconha, cocaína, crack, merla, entre outras.

Relatos apontaram que alguns clientes pagam por um programa para, apenas, utilizarem cocaína ou crack em função de terem receio a uma 
overdose e, nestas situações, a presença da profissional do sexo se configura como uma forma de proteção ao usuário/cliente. Nessa perspectiva, Guedes et al. (2013) e Tang et al. (2015) destacaram em seus estudos que, muitas vezes, durante o ato sexual com prostitutas, os clientes estão alcoolizados ou sob efeito de outra droga.

Dourado et al. (2013, p. 4142) corroboram com o exposto afirmando que:

O uso de substâncias psicoativas na atividade de prostituição é um fenômeno inerente que sofre interferências de diversos fatores, como o incentivo por parte dos clientes, traficantes e proprietários dos estabelecimentos. Essa situação potencializa as vulnerabilidades das prostitutas às situações de violências, a DST e outros agravos.

No que tange ao consumo de álcool e/ou de drogas em programas de prostituição, diversos autores citam que tais substâncias estão relacionadas de forma negativa com situações de violência, seja na produção de conflitos quanto em condutas violentas (DOURADO et al., 2013; CONNERS et al., 2016; LIMA et al., 2017).

Quando sob efeito de álcool ou outras drogas, as profissionais do sexo também estão vulneráveis às IST, visto que realizam atos sexuais de forma menos cuidadosa, incluindo o não uso do preservativo, ou culminando em acidentes com esses protetores (CHERSICH et al., 2014), configurando outra importante vulnerabilidade.

Relatos evidenciaram que os clientes evitam usar o preservativo masculino, tiram ou forçam para estourá-lo. Motivos para o sexo desprotegido, geralmente, estão atrelados ao fato de os clientes não gostarem de utilizar este método de barreira por julgarem que atrapalha na ereção e sensibilidade, interferindo no prazer. Andrews et al. (2015) referem que a diminuição do prazer do cliente durante o ato sexual é a maior causa para o não uso de preservativo por algumas profissionais do sexo, quando solicitado pelo cliente.

Conforme relatos, os clientes tentam as mais diversas formas de negociação para não utilizarem o preservativo, oferecendo, inclusive, valores mais altos pelos programas. Algumas vezes tal negociação é aceita pelas mulheres, que alegam necessidade financeira. Diante de ofertas de clientes para a prática oral e/ou sexual desprotegida, pesquisa de Moura et al. (2010, p. 550) concluiu que "as prostitutas recebem propostas que, para elas, são irrecusáveis".

Beyrer et al. (2015) também verificaram que profissionais do sexo possuem um risco aumentado para infecção pelo HIV e outras infecções transmitidas através do ato sexual. Esse risco é maior, pois clientes atendidos por estas profissionais, muitas vezes, negam-se a utilizar o preservativo, além 
de ser um público que, por procurar outros profissionais do sexo, associada à prática sexual desprotegida, estão mais propensos a serem portadores do HIV e, desta forma, transmití-lo pelo ato sexual (DECKER et al., 2015). Profissionais do sexo lidam diariamente com diferentes clientes que possuem trajetórias sexuais ignoradas, fato que as classifica como grupo vulnerável (MOURA et al., 2010).

Shannon et al. (2015) também reforçam que as profissionais do sexo apresentam maiores prevalências e incidências de infecção por HIV e, assim como outros autores, atribuem como causas desse dado o maior risco de violência sexual e, principalmente, propostas de pagamento adicional pelos seus serviços quando o cliente não utiliza o preservativo. A não utilização de um método de barreira durante as relações configura risco de contaminação pelo HIV em função de vulnerabilidades de cunho estrutural, individual e interpessoal (POTEAT et al., 2015).

É importante ressaltar que a temática HIV se destaca quando se trata da violência sexual, visto que esse tipo de abuso acontece sem o uso de preservativo (CONNERS et al., 2016). Ainda sobre as IST, relatos das profissionais reforçaram que o sexo oral nem sempre é realizado com o preservativo masculino, possibilitando a contaminação pelo papilomavírus (HPV), bem como por outras doenças.

As rodas de conversa apontaram para sinais e sintomas indicativos de IST, manifestados por secreções vaginais fétidas, coceiras, entre outros achados. Essa condição é o que remete o estudo de Moura et al. (2010) ao passo que o aumento da secreção vaginal, juntamente de odor fétido caracteriza quadro que mais acomete e incomoda as prostitutas, além de prejudicar o ganho financeiro pela necessidade em pausar o trabalho por alguns dias, até o reestabelecimento da saúde.

Outro fator que vulnerabiliza as profissionais do sexo às IST é o uso (consentido ou por iniciativa própria) de drogas injetáveis, com compartilhamento de seringas. De acordo com West et al. (2015), na maioria das vezes, o compartilhamento ocorre com os próprios clientes. Prática que, em muitos casos, pode predispor essas mulheres a uma dependência à droga utilizada. Outro resultado dessa prática é a transmissão de doenças infecciosas, geralmente de origem viral, por meio da via hematogênica, sendo os principais agentes infectantes o HIV e as hepatites possíveis de serem transmitidas por essa via (B e C) (WEST et al., 2015).

Quando se trata de prática sexual realizada com parceiro fixo, namorado ou marido, os relatos das profissionais divergiram quanto ao uso de preservativo nas relações. Nem sempre esta barreira é utilizada e tal fato se deve a questões culturais, afetivas e a uma relação de confiança (MOURA et al., 2010).

Algumas profissionais já realizaram abortos em situações de rompimento do preservativo ou em casos de relação sexual desprotegida 
que resultou em gravidez. Em estudo realizado por Madeiro e Rufino (2012), na capital piauiense, 52,6\% das profissionais do sexo já tiveram aborto induzido, e algumas realizaram a prática mais de uma vez. As formas de abortos, nestes casos, ocorreram por meio da utilização de misoprostol $\left(\right.$ Cytotec $\left.^{\circledR}\right)$ intravaginal ou oral, de ingestão de chás (diversos), pelo uso de sondas e por curetagem uterina em clínicas clandestinas, com internação hospitalar (MADEIRO; RUFINO, 2012).

Quanto ao sentimento de prazer durante os programas, para algumas, tal fato é proibido, mas para outras não. Nessa perspectiva, Burbulhan, Guimarães e Bruns (2012) destacaram que a maioria das profissionais do sexo procura não se envolver pessoalmente com a relação. Para isso, elas evitam sentir prazer e ter orgasmo durante o trabalho, mantendo apenas o caráter profissional do momento. Quando o orgasmo é atingido, elas interpretam tal fato como um "acidente de trabalho". Para evitar isso, controlam o tempo, a posição e os carinhos para com o cliente a fim de que esse tenha o seu gozo adiantado (BURBULHAN; GUIMARÃES; BRUNS, 2012) e o programa tenha um desfecho rápido.

A saúde mental das profissionais do sexo também pode ser afetada. Decker et al. (2015) apontam vulnerabilidades que se constituem em alto risco de homicídio devido à grande marginalização social; repressão, extorsão, humilhação e detenção policial forçada, impunidade e discriminação no acesso à justiça, discriminação no acesso aos serviços de saúde, além de lei que criminaliza e pune o trabalho de origem sexual.

Estes fatores mencionados corroboram como causas de problemas que afetam o bem-estar psicológico dessas mulheres. Com isso, estas apresentam ansiedade, depressão, atitudes violentas, ideias suicidas, além de passarem a fazer uso de substâncias lícitas (álcool) e ilícitas (outras drogas), como forma de fuga (POTEAT et al., 2015).

Diante das diversas vulnerabilidades expostas neste estudo, torna-se importante conhecer como as profissionais do sexo participantes das rodas de conversa enfrentam tais situações.

\section{Enfrentamento das vulnerabilidades}

Há escassez de estudos que tratem das habilidades de resiliência e de enfrentamento das vulnerabilidades de prostitutas que atuam na rua (LOVE, 2015). No que concerne às vulnerabilidades relacionadas a questões morais e sociais, observou-se que as falas das profissionais do sexo remeteram a formas de enfrentamento da sociedade, tanto no sentido de considerarem tal trabalho como qualquer outro, quanto a respeito da necessidade de quebra de paradigma e de preconceitos ainda existentes.

No intuito de evitarem ser alvo de preconceitos por parte da sociedade, bem como de familiares, as mulheres participantes alegaram ter 
sua vida profissional estritamente separada da vida pessoal e social, como se adotassem personagens diferentes em cada contexto.

Heilborn (2006) defende que o sexo deve ser encarado como qualquer outra atividade humana que é aprendida, a exemplo da alimentação e da higiene pessoal. A mesma autora ainda pondera que a cultura norteia percursos e comportamentos, socializando os sujeitos para o início da vida sexual. Tal fato faz com que cada sociedade visualize e exerça as práticas sexuais de uma forma, variando conforme a referência de cada parcela desta (HEILBORN, 2006).

Sobre as formas de enfrentamento decorrentes da relação das profissionais do sexo com os clientes, Burbulhan, Guimarães e Bruns (2012) afirmam que esse relacionamento varia conforme cada cliente e, geralmente, está intrinsecamente relacionado à forma de tratamento destes para com elas. Se os clientes as tratam bem, elas os tratam da mesma maneira e a relação é boa; mas, em situação inversa, a relação entre ambos também se modifica.

Entrevistas realizadas com 21 homens acerca das experiências de aprendizado sexual desvelaram que muitas das relações sexuais de iniciação destes indivíduos aconteceram com prostitutas (COROSSACZ, 2014). Estas, além de terem sido marcadas por violência, foram baseadas "[...] na desigualdade da experiência sexual entre homens e mulheres e na definição da sexualidade feminina como funcional em relação à masculina”, abrigando, além do exposto, uma condição de domínio (COROSSACZ, 2014, p. 538).

Assim como verificado na roda de conversa realizada com as profissionais do sexo, pesquisa realizada por Benoit et al. (2017), com 218 profissionais do sexo, no Canadá, verificou que existe relação entre o trabalho e a autoestima. As participantes das rodas de conversa alegaram que a autoestima se eleva com o trabalho sexual e a pesquisa de Benoit et al. (2017) também constatou relação entre trabalho sexual e autoestima.

Relatos deste estudo deixaram evidente que existem muitos meios de evitar os diversos tipos de violência, mas que, mesmo assim, episódios ocorrem. Há relatos de casos de defesas de violência sofrida por cliente utilizando-se de agressão com arma branca.

De acordo com Dourado et al. (2013, p. 4141):

A violência na prostituição configura-se em problemática cuja essência não é meramente um discurso social, mas parte de uma trajetória feminina de exposição ao poder masculino que cria uma relação mediada pelo desejo ao corpo, pela satisfação dos prazeres sexuais e pela relação de poder por dinheiro ou qualquer outro bem.

Estratégias de cumplicidade entre as profissionais servem como forma de enfrentamento e de proteção e envolvem avisar umas às outras 
sobre os clientes que são violentos. Ainda, quando as profissionais estão em programa no quarto do motel e sentem-se ameaçadas, retiram o interfone do gancho sinalizando um pedido de socorro. Tal ação funciona como um código para a recepção do motel saber que estão em perigo e precisam de ajuda e, o apoio se dá com a ida de uma camareira até o quarto. Com isso, notou-se que os donos dos motéis configuram importante rede de apoio para essas profissionais.

Nos casos de exposição a bebidas, há relatos de clientes que tentam entorpecer as profissionais do sexo no intuito de aproveitarem o programa para realizarem práticas que não seriam permitidas se estas estivessem sóbrias. Em alguns casos, quando oferecida alguma bebida pelos clientes, as profissionais relataram que ludibriam estar ingerindo uisque, quando, na verdade, estão ingerindo refrigerante ou, ainda, trocam vodka por água. Shannon et al. (2015) aponta para a necessidade de informar as profissionais sobre os resultados orgânicos que o uso de drogas (lícitas e ilícitas) podem gerar.

Quando questionadas se faziam uso de bebidas alcoólicas nos programas, houve divergência nas respostas, sendo que algumas mencionaram não fazer uso e outras disseram que fazem uso, mas que são resistentes às bebidas alcoólicas. Quanto ao uso de drogas nos programas, as participantes das rodas alegaram que não utilizam.

Nos casos de vulnerabilidades relacionadas a possíveis contaminações por alguma IST, observou-se que, assim como nos casos de violências, também existe uma medida protetiva entre as profissionais do sexo a fim de evitarem a contaminação por doenças a partir de clientes que já, sabidamente, são acometidos. Estas trocam informações entre si e avisam umas às outras sobre os casos de clientes "contaminados".

Mas, independentemente desta medida protetiva utilizada pelas profissionais, ressalta-se que as formas de prevenção para as IST perpassam pela obrigatoriedade do uso do preservativo em todos os tipos de relacionamentos sexuais (SU et al., 2016), de forma constante, mesmo que essas mulheres nem sempre compreendam as informações quanto aos cuidados para uma proteção (SHANNON et al., 2015).

Ressalta-se a necessidade de implementação de políticas públicas amplas que envolvam questões sociais, econômicas e de saúde, que busquem formas de estruturar melhor a chegada e o entendimento das informações sobre prevenção, segurança, administração financeira pessoal e de autoestima a fim de que as profissionais do sexo sintam-se seguras, com estabilidade financeira e aceitação da profissão perante a família, os amigos e a sociedade (SHANNON et al., 2015).

Nesse contexto, salienta-se a importância do componente programático como uma forma de enfrentamento à vulnerabilidade de 
contaminação por IST, por meio do papel apoiador do GAPA. Este Grupo, por sua vez, age orientando as profissionais do sexo quanto à importância de se prevenirem contra a contaminação por HIV e outras IST, principalmente pela transmissão que ocorre através do ato sexual. Porém, quando tal prevenção não ocorre e alguma doença se manifesta, existe a necessidade das profissionais realizarem tratamentos para sanar o problema. Ademais, estas mulheres relataram que, para acometimentos de ordem sexual e manifestações decorrentes de vaginoses, adotam medidas profiláticas fazendo uso de medicações de caráter controlado e de forma rotineira.

Quando identificam que o cliente pode estar potencialmente contaminado por alguma IST, evitam manipulação do órgão do cliente sem preservativo e contato direto do pênis com a região vaginal, adotandose a posição de quatro apoios com vistas a abreviar o tempo da relação e minimizar o contato.

Ainda, as profissionais do sexo afirmaram que se higienizam para se sentirem limpas após os programas e como forma de evitarem a contaminação por alguma doença. Outras urinam antes e após as relações sexuais como prevenção de infecção do trato urinário.

Sobre os cuidados relacionados à saúde e ao bem-estar, pesquisa etnográfica realizada com oito profissionais do sexo atuantes na cidade de Santa Maria/RS apontou contextos diversos, sendo classificados como: cuidados oriundos do domicílio e aprendidos com a família; cuidados da vida, decorrentes da experiência na prostituição e do labor com colegas; e cuidados disseminados por profissionais dos serviços de saúde (BONADIMAN; MACHADO; LÓPEZ, 2012). Os cuidados mencionados e realizados pelas profissionais do sexo participantes das rodas de conversa são passíveis de serem alocados de acordo com a classificação proposta por Bonadiman, Machado e López (2012), visto que se configuram em práticas realizadas a partir de um contexto empírico, mas que salvaguardam um propósito científico e visam a evitar o surgimento de quadros infecciosos.

Nas situações em que ocorre o rompimento do preservativo ou nos casos de relação sexual desprotegida, a fim de evitar uma gravidez indesejada, as profissionais afirmaram fazer uso da pílula do dia seguinte, que é cobrada do cliente, no ato do pagamento referente ao programa.

Ainda nesse contexto, nas situações em que o cliente solicita ejacular em alguma parte do corpo da mulher, sem utilizar preservativo, quando o ato se dá próximo ao órgão vaginal, as profissionais afirmaram colocar a mão na vagina de maneira a impedir a entrada de secreções espermáticas. Salienta-se, no entanto, que esta atitude se configura em ideia de falsa proteção.

No que concerne à questão do prazer, algumas mulheres afirmaram que, embora não seja uma prática frequente, aproveitam o momento da 
relação com alguns clientes para chegarem ao clímax, visto que também têm direito de aproveitar a situação e não apenas vender seus corpos para prazer alheio. Nesse sentido, Heilborn (2006) aborda que o exercício sexual de homens e mulheres é guiado por temas ligados ao gênero e à discrepância nas relações existentes entre homens e mulheres.

Ressalta-se que, apesar de todas as vulnerabilidades apontadas neste artigo, as profissionais do sexo possuem conhecimento de vida, agilidade para as negociações e habilidades para envolver o sexo oposto (NASCIMENTO; GARCIA, 2015), fato que favorece que elas enfrentem as adversidades e os desafios decorrentes do trabalho de forma exitosa. Finalmente, outras formas de enfrentamento advêm do apoio das colegas de trabalho, de membros da família, bem como de amigas.

\section{Considerações finais}

A partir dos relatos de profissionais do sexo atuantes na rua e no meio urbano, foi possível perceber vulnerabilidades a que estas mulheres estão expostas e vivenciam, incluindo aspectos ligados a questões de gênero e de poder, de situações que envolvem violência física, sexual e moral, com exposição a agravos relacionados à saúde física e emocional.

Da mesma forma que se observou uma complexidade de variáveis influenciando nas situações de vulnerabilidade, constatou-se que muitos são os meios de enfrentamento perante as diferentes situações vivenciadas. Destacam-se as estratégias de cumplicidade utilizadas entre as profissionais como importante forma de enfrentamento e de proteção.

Ademais, percebeu-se que o modo como as profissionais do sexo enfrentam as adversidades impostas pelas vulnerabilidades é, majoritariamente, passado de uma mulher para outra, de posse das experiências e vivências de cada uma. Embora haja uma rede de proteção estabelecida pelas próprias profissionais e pelo GAPA, ficaram explícitas as vulnerabilidades de ordem individual, social e programática a que estão expostas essas profissionais.

Salienta-se a importância de desenvolvimento de estudos subsequentes que contribuam com a abordagem científica sobre a temática abordada, extrapolando o empirismo e promovendo ações que possam auxiliar estas profissionais a enfrentarem, além das muitas barreiras individuais, familiares e sociais, o seu trabalho de forma digna, saudável, sem estereotipias, julgamentos e/ou preconceitos.

\section{Agradecimentos}

Às profissionais do sexo pela disponibilidade e acolhida, aos funcionários do Grupo de Apoio à Prevenção da AIDS (GAPA) - seção 
Chapecó, ao Programa de Pós-Graduação em Ciências da Saúde da Universidade Comunitária da Região de Chapecó (UNOCHAPECÓ) e à Coordenação de Aperfeiçoamento de Pessoal de Nível Superior (Capes).

\section{Referências}

ANDREWS, C. H. et al. Determinants of consistente condom use among female sex workers in Sacannakhet, Lao PDR. BMC Women's Health, v. 15, n. 63, p. 1-8, 2015.

AYRES,J.R. C.M. et al. O conceito de vulnerabilidade e as práticas de saúde: novas perspectivas e desafios. In: CZERESNIA, D.; FREITAS, C. M. de. Promoção da saúde: conceitos, reflexões, tendências. 2. ed. Rio de Janeiro: Editora Fiocruz, 2009. p. 121-143.

BARDIN, L. Análise de conteúdo. São Paulo. Edições 70, 2011.

BENOIT, C. et al. Sex work and three dimensions of self-esteem: self-worth, authenticity and self-efficacy. Culture, Health \& Sexuality, v. 0, n. 0, p. 1-15, may. 2017.

BEYRER, C. et al. $\mathrm{Na}$ action agenda for HIV and sex work. Lancet, v. 385, n. 9964, p. 287-301, jan. 2015.

BONADINAM, P. O. B.; MACHADO, P. S.; LÓPEZ, L. C. Práticas de saúde entre prostitutas de segmentos populares da cidade de Santa Maria-RS: o cuidado em rede. Physis Revista de Saúde Coletiva, v. 22, n. 2, p. 779-801, 2012.

BRASIL. Ministério do Trabalho e Emprego. Classificação Brasileira de Ocupação. Brasília: Ministério do Trabalho e Emprego, 2017.

BROWN, K; SANDERS, T. Pragmatic, Progressive, Problematic: Addressing Vulnerability through a Local Street Sex Work Partnership Initiative. Social Policy and Society, v. 16, n. 3, p. 1-13, feb. 2017.

BURBULHAN, F.; GUIMARÃES, R. M.; BRUNS, M. A. de T. Dinheiro, afeto, sexualidade: a relação de prostitutas com seus clientes. Psicologia em Estudo, v. 17, n. 4, p. 669-677, out./dez. 2012.

CHANG, H. H.; WENG, Y. Working in the Dark: A Look at the Violence Risk of the Street Prostitution Service. Journal of Social Service Research, v. 41, n. 4, p. 545-555, jun. 2015.

CHERSICH, M. F. et al. Effects of hazardous and harmful alcohol use on HIV incidence and sexual behaviour: a cohort study of Kenyan female sex workers. Globalization and Health, v. 10, n. 22, p. 1-11, 2014.

CONNERS, E. E. et al. Structural determinants of cliente perpetrated violence among female sex workers in two Mexico-U.S. Border Cities. AIDS Behav, v. 20, p. 215-224, 2016.

COROSSACZ, V.R. Cor, classe, gênero: aprendizado sexual e relações de domínio. Estudos Feministas, v. 22, n. 2, p. 521-542, maio/ago. 2014.

DECKER, M. R. et al. The lancet series on HIV in sex workers: paper 4 burden and HIV impact of human rights violations against sex workers. Lancet, v. 385, n. 9963, p. 186-199, jan. 2015. 
DOURADO, G. O. L. et al. Prostituição e sua relação com o uso de substância psicoativas e a violência: revisão integrativa. Rev enferm UFPE on line, v. 7, n. especial, p. 4138-4143, maio 2013.

FERNANDES, L. A. B.; BORGES, Á. A. da C.; LÔBO, R. P. B. Travestilidade às avessas - a desconstrução de uma "paródia" identitária. Estudos Feministas, v. 25, n. 2, p. 473-494, maio/ago. 2017.

GRUPO DE APOIO À PREVENÇÃO DA AIDS (GAPA). Disponível em: http://gapachapeco.blogspot.com.br. Acesso em: 22 jun. 2017.

GUEDES, H. M. et al. Uso de preservativo entre frequentadores de um motel. Rev. enferm. UERJ, v. 21, n. 2, p. 241-246, abr./jun. 2013.

HEILBORN,M.L.Entre as tramas da sexualidade brasileira.Estudos Feministas, v. 1, n. 14, p. 43-59, jan./abr. 2006.

LIMA, F. S. da S. L. et al. Fatores associados à violência contra mulheres profissionais do sexo de dez cidades brasileiras. Caderno Saúde Pública, v. 33, n. 2, p. 1-16, mar. 2017.

LOVE, R. Street Level Prostitution: A Systematic Literature Review. Journal Issues in Mental Health Nursing, v. 36, n. 8, p. 568-577, sep. 2015.

MADEIRO, A. P.; RUFINO, A. C. Aborto induzido entre prostitutas: um levantamento pela técnica de urna em Teresina-Piauí. Ciência e Saúde Coletiva, v. 17, n. 7, p. 1735-1743, 2012.

MALAGÓN-OVIEDO, R. A.; CZERESNIA, D. O conceito de vulnerabilidade e seu caráter biossocial. Interface, v. 19, n. 53, p. 237-249, jun. 2015.

MOURA, A. D. A. et al. O comportamento de prostitutas em tempos de AIDS e outras doenças sexualmente transmissíveis: como estão se prevenindo? Texto Contexto Enfermagem, v. 19, n. 3. p. 545-553, jul./set. 2010.

NASCIMENTO, S. de S.; GARCIA, L. G. Nas armadilhas do desejo: privações e movimentos de jovens prostitutas em zonas rurais. Caderno CRH, v. 28, n. 74, p. 383-396, maio/ago. 2015.

POTEAT, T. et al. HIV risk and preventive interventions in transgender women sex workers. Lancet, v. 385, n. 9964, p. 274-286, Jan. 2015.

SÁNCHEZ, A. I. M.; BERTOLOZZI, M. R. Pode o conceito de vulnerabilidade apoiar a construção do conhecimento em Saúde Coletiva? Ciência e Saúde Coletiva, v. 12, n. 2, p. 319-324, 2007.

SHANNON, K. et al. Global epidemiology of HIV among female sex workers: influence of structural determinants. Lancet, v. 385, n. 9962, p. 55-71, jan. 2015.

SILVA, K. A. T.; CAPPELLE, M. C. A. Sentidos do trabalho apreendidos por meio de fatos marcantes na trajetória de mulheres prostitutas. RAM Rev. Adm. Mackenzie, v. 16, n. 6, p. 19-47, nov./dez. 2015.

SU, S. et al. Sustained high prevalence of viral hepatites and sexually transmissible infections among female sex workers in China: a systematic review and metaanalysis. BMC Infectious Diseases, v. 16, n. 2, p. 1-10, 2016. 
TANG, Z. et al. HIV risk among female sex workers with different patterns of drug use behaviors in Southwest China: a cross-sectional study. AIDS Care, v. 27, n. 3, p. 293-300, mar. 2015.

VÍCTORA, C. G. Pesquisa qualitativa em saúde: uma introdução ao tema. Porto Alegre: Tomo Editorial, 2000.

WEST, B. S. et al. Predictors of injection cessation and relapse among female sex workers who inject drugs in two Mexican-US border cities. Journal of Urban Health: Bulletin of the New York Academy of Medicine, v. 93, n. 1, p. 141-154, 2015.

Submetido em: 06/08/2018

Aceito em: 31/05/2019 


\title{
SEX WORKERS: PARTAKERS AS A WAY OF COPING WITH VULNERABILITIES
}

\begin{abstract}
This article aims to analyze the vulnerabilities in the work of street sex workers and their ways of coping. This is a qualitative, cross-sectional and reflective study. Ten women participated in two dialogue circles. The meetings were held in april, 2017, in drive-in motels in the city of Chapecó, Santa Catarina, Brazil. The information was collected through a questionnaire, recorded in a field diary and submitted to thematic content analysis. The authors conducted a subjective and critical reflexive analysis of the data. Two themes emerged: "The work vulnerabilities" and "Coping with vulnerabilities". The sex workers reported individual, social and work-related vulnerabilities, which included aspects related to gender and power issues, situations involving physical, sexual and moral violence, and exposure to physical and emotional abuse. Numerous variables influenced the situations of vulnerability, but there were also many ways of coping with the different situations. The experiences of each woman revealed that partakers between these professionals is an important form of coping and protection.
\end{abstract}

Keywords: Sex work. Risk groups. Health Vulnerability. Sexually Transmitted Infections. Violence.

\section{PROFESIONALES DEL SEXO: LA COMPLICIDAD COMO ENFRENTAMIENTO DE LAS VULNERABILIDADES}

\begin{abstract}
Resumen
Este artículo objetiva analizar las vulnerabilidades del trabajo de profesionales del sexo actuantes en la calle y sus formas de enfrentamiento. Se trata de un estudio cualitativo, transversal y reflexivo. Diez mujeres participaron de dos encuentros que tuvieron lugar en la modalidad rueda de conversación, en abril de 2017, en moteles del tipo drive in, en el municipio de Chapecó, Santa Catarina, Brasil. Las informaciones fueron recolectadas por medio de un cuestionario, registros en diario de campo y sometidas al análisis de contenido del tipo temático. La interpretación de los datos se dio por subjetividad y análisis reflexivo crítico de los autores, desvelándose dos temas: "Las vulnerabilidades del oficio" y el "Enfrentamiento de las vulnerabilidades". Las profesionales del sexo relataron vulnerabilidades de orden individual, social y programático, incluyendo aspectos relacionados a cuestiones de género y de poder, de situaciones que involucran violencia física, sexual y moral, además de exposición a agravios relacionados a la salud física y emocional. Se observó una complejidad de variables que involucran en las situaciones de vulnerabilidad, pero también muchas formas de enfrentamiento ante las diferentes situaciones vivenciadas. A partir de las experiencias y vivencias de cada mujer, se destacan las estrategias de complicidad utilizadas entre las profesionales como importante forma de enfrentamiento y de protección.
\end{abstract}

Palabras-clave: Trabajo sexual. Grupos de riesgo. Vulnerabilidad en salud. Infecciones Sexualmente Transmisibles. Violencia. 